\title{
SPECIES DICROGLOSSIDAE (AMPHIBIA) PADA ZONA PEMANFAATAN TNKS DI WILAYAH SOLOK SELATAN
}

\author{
SPECIES DICROGLOSSIDAE (Amphibian) ON TNKS \\ UTILITATION ZONE IN THE SOUTH SOLOK
}

\author{
Meliya Wati \\ Program Studi Pendidikan Biologi STKIP PGRI Sumatera Barat. \\ Jl. Gunung Pangilun Padang, Kota Padang, Sumatera Barat, Indonesia. \\ Telp./Fax. (0751) 7053731/ (0751) 7053826. \\ e-mail : meliyawatibio0310@gmail.com \\ Manuskript diterima : 4 Oktober 2016. Revisi disetujui 15 November 2016
}

\begin{abstract}
Amphibians are kind of export commodity that was great, because Indonesian exports frog up thousands of tons each year. The frogs were exported are largebodied species of frogs obtained from cultivation and captured directly from their habitat. Meanwhile, types of great frogs in general of a group of families Dicroglosidae in southern Solok region is part of the national park area kerinci seblat namely the utilization zone. In this area found a lot of types of frogs, including the type of Dicroglossidae. Amphibians search by visual methods ecounter Survey (VES) is focused on the path specified, by walking in a location which is widely expected at 18:00 to 23:00 pm. Based on the results of the study found five species Dicroglosidae in the Utillitation Zone in South Solok TNKS Region, including Fejervarya limnocharis, limnonectes Ingeri, limnonectes macrodon, limnonectes ibanorum, limnonectes shompenorum.
\end{abstract}

Key Word: Familia Dicrolossidae, Utillitation Zone, South Solok

\begin{abstract}
ABSTRAK
Amphibia merupakan jenis komoditi ekspor yang cukup besar, karena indonesia mengekspor katak hingga ribuan ton tiap tahunnya. Katak-katak yang diekspor adalah jenis katak berbadan besar yang diperoleh dari pembudidayaan dan ditangkap langsung dari habitatnya. Sementara, jenis-jenis katak berbadab besar pada umumnya dari kelompok famili Dicroglosidae. Kawasan solok selatan merupakan bagian dari kawasan taman nasional kerinci seblat yaitu zona pemanfaatan. Pada daerah ini ditemukan banyak sekali jenis-jenis katak, termasuk jenis dari Dicroglossidae. Pencarian Amphibia dengan metode visual ecounter survey (VES) difokuskan pada jalur yang sudah ditentukan, dengan cara berjalan pada suatu lokasi yang diduga banyak Amphibianya pada malam hari dari pukul 18.00 - 23.00 WIB. Berdasarkan hasil penelitian ditemukan 5 spesies Dicroglosidae di Zona Pemanfaatan di Kawasan TNKS Solok Selatan, diantaranya Fejervarya limnocharis, Limnonectes ingeri, Limnonectes macrodon, Limnonectes ibanorum, Limnonectes shompenorum.
\end{abstract}

Kata Kunci: Familia Dicrolossidae, Zona Pemanfaatan, Solok Selatan 


\section{PENDAHULUAN}

Amphibia merupakan hewan yang memiliki habitat hidup di dua alam yaitu air dan darat. Selama siklud hidupnya, Amphibia berada dalam air dan bernapas dengan insang sedangkan setelah dewasa hidup di darat dan bernapas dengan paruparu dan kulit. Amphibia dibagi atas 3 Ordo yaitu Caudata (Urodela), Sesilia (Gymnophiona) dan Anura (Salienta) (Brotowidjoyo, 1994). Ketiga ordo Amphibia yang ditemukan di dunia hanya 2 Ordo yang terdapat di Indonesia yaitu Anura dan Sesilia. Ordo Anura merupakan Ordo Amphibia yang terbesar dan sangat beragam, terdiri dari lebih 4.100 species. 30 familia Anura yang telah dikenal, sepuluh terdapat di Indonesia (450 species) (Iskandar, 1998). Sesilia terdiri dari 159 species, yang terdapat di Indonesia hanya 30 species yang tersebar di Jawa, Kalimantan dan Sumatera (Iskandar, 2008).

Amphibia di Sumatera kurang diteliti dibandingkan di pulau Jawa. Hal ini terlihat dari tabulasi Amphibia dari Ordo Anura yang hanya berjumlah (90 species), ini jauh lebih kecil jika dibandingkan dengan Anura yang telah diketahui di Kalimantan yaitu 148 Species dengan luas daerah yang lebih besar dan semenanjung Malaysia dengan 101 Species dengan luas area yang lebih kecil (Inger and Voris, (2001), dalam Wanda, 2012). Tingginya proporsi dari hewan endemik di Sumatra yaitu sebesar 20,3\% menjadikan pulau Sumatera menempati peringkat pertama dalam hal kekayaan species dari hewan-hewan Herpetofauna untuk kawasan Asia (David dan Vogel (1996) dalam Wanda, 2012)

Habitat utama Amphibia adalah hutan primer, hutan sekunder, hutan rawa, sungai besar, sungai sedang, anak sungai, kolam dan danau (Mistar 2003). Iskandar (1998) menyatakan bahwa Amphibia selalu hidup berasosiasi dengan air sesuai namanya yaitu hidup pada dua alam (di air dan di darat). Selanjutnya dijelaskan bahwa sebagian besar Amphibia didapatkan hidup di kawasan hutan karena disamping membutuhkan air juga membutuhkan kelembaban yang cukup tinggi (7585\%) untuk melindungi tubuh dari kekeringan. Amphibia juga membutuhkan suhu tertentu untuk mendapatkan pertumbuhan yang maksimum berkisar $26^{\circ} \mathrm{C}-33^{\circ} \mathrm{C}$ (Berry (1975) dalam Sardi, Erianto, dan Siahaan, 2013) dan suhu air $20^{\circ} \mathrm{C}-35^{\circ} \mathrm{C}$ (Kanna (2005) dalam Sardi, Erianto, dan Siahaan, 2013).

Taman Nasional Kerinci Seblat merupakan Taman Nasional yang berada di 
Tiga Provinsi yaitu Jambi, Bengkulu dan Sumatera Barat. Berdasarkan pengelolaan Taman Nasional wilayah IV Sumatera Barat TNKS berada pada tiga Kabupaten yaitu Kabupaten Solok, Dharmasraya dan Kabupaten Solok Selatan. Taman Nasional Kerinci Seblat (TNKS) merupakan salah satu taman nasional yang dapat berperan aktif dalam peningkatan pendapatan negara dari sektor wisata alam, TNKS merupakan Taman Nasional yang memiliki potensi wisata yang menarik dan telah ditetapkan zonasinya dalam mendukung pengelolaan wisata alam. Sesuai dengan Keputusan Direktur Jenderal Perlindungan Hutan dan Konservasi Alam No. SK.07/IV-KK/2007 tentang zonasi TNKS, wilayah TNKS di Kabupaten Solok Selatan seluas 69.234,53 Ha yang secara detailnya yaitu zona Inti (13.089,34 Ha), Zona rimba (35.094,97 Ha), Zona Rehabilitas (16. 865,13 Ha), Zona Khusus (1.790,13 Ha), Zona Tradisional (1.790,13 Ha) dan Zona Pemanfaatan (490,72 Ha). Salah satu dari keenam zona tersebut, Zona pemanfaatan yang terletak di Kabupaten Solok Selatan akan dijadikan tempat wisata dan lahannya sudah dipergunakan oleh masyarakat untuk lahan perkebunan (Anonim, 2015)

Observasi menunjukkan permasalahan terhadap wilayah kawasan pemanfaatan yaitu pembukaan lahan untuk objek wisata dan adanya lahan pertanian di kawasan TNKS oleh masyarakat setempat, hal ini akan berdampak buruk terhadap satwa yang hidup di kawasan TNKS, salah satunya kehidupan dari Amphibia. Masalah ini berkaitan dengan peralihan lahan hutan menjadi lahan pertanian, yang mana hutan merupakan habitat asli dari species-species Amphibia. Habitat dari Amphibia ini selalu berkaitan dengan kegiatan manusia (Iskandar, 1998). Di kawasan TNKS fauna yang terdapat di wilayah ini salah satunya adalah dari species Amphibia. Species yang teridentifikasi yaitu species katak Bertanduk Sumatera, katak sungai bertotol dan katak jeram. Namun dikawasan Zona Pemanfaatan TNKS Gunung Bontak yaitu di Jorong Pincuran Tujuh, Kecamatan Sangir Kabupaten Solok Selatan belum teridentifikasi Species-species dari Amphibia (Anonim, 2015).

Dilihat dari fenomena sekarang ini Amphibia merupakan jenis komoditi ekspor yang cukup besar, karena indonesia mengekspor katak hingga ribuan ton tiap tahunnya. Katak-katak yang diekspor adalah jenis katak berbadan besar yang diperoleh dari pembudidayaan dan ditangkap langsung dari habitatnya. Sementara, jenis-jenis katak berbadab besar pada umumnya dari kelompok famili dogrolosidae. 
Kawasan solok selatan merupakan bagian dari kawasan taman nasional kerinci seblat yaitu zona pemanfaatan. Pada daerah ini ditemukan banyak sekali jenis-jenis katak, termasuk jenis dari dogrolosidae. Dengan demikian kawasan tersebut berpotensi untyk dijadikan kawasan budidaya katak, sehingga dapat mengurangi kepunahan katak digrolosidae di habitat aslinya.

\section{BAHAN DAN METODE}

\section{Alat dan Bahan}

Alat yang digunakan dalam penelitian ini adalah senter, pisau, parang, karung, tangguk, meteran, tali rafia, sarung tangan, kapas, botol koleksi, batrai, kertas label, kantong plastik, kotak plastik, karet gelang, suntik, kamera digital jangka sorong dan seperangkat alat tulis. Bahan yang digunakan adalah Kloroform dan alkohol 70\% dan 96\% untuk pembiusan dan pengawetan Amphibia.

\section{Rancangan Penelitian}

Penelitian ini adalah penelitian Survei langsung terhadap species Amphibia yang didapat di lokasi, dengan menggunakan metode visual ecounter survey (VES) yang dikombinasikan dengan sistem jalur dengan metode purposive random sampling. Visual ecounter survei yakni suatu metode standar dalam metode lapangan Amphibia yang dapat meliputi semua mikrohabitat pencarian seperti pada tanah, air, bagian bawah dari lapisan serasah, dilakukan dengan berjalan pada suatu habitat atau area secara bebas dengan jumlah waktu pencarian yang disesuaikan dengan luas daerah.

\section{Prosedur Penelitian}

Pencarian Amphibia dengan metode visual ecounter survey (VES) difokuskan pada jalur yang sudah ditentukan, dengan cara berjalan pada suatu lokasi yang diduga banyak Amphibianya pada malam hari dari pukul 18.00 - 23.00 WIB, semua Amphibia yang terlihat akan dikoleksi. Untuk penangkapan species Anura dengan cara Anura yang terlihat disinari dengan senter agar buta sesaat dan tidak meloncat. Penangkapan dapat dilakukan dari bagian belakang maupun bagian depan. Sedangkan untuk penangkapan Sesilia yaitu ditangkap langsung menggunakan tangan. Pencarian dilakukan 3 kali dalam seminggu. Pencarian telah dihentikan karena tidak ditemukan lagi species baru dari pencarian sebelumnya. Sampel yang didapatkan dimasukkan ke dalam kantung plastik per individu, pencatatan data-data 
ekologi juga dilakukan seperti suhu, kelembaban, bentuk habitat, dan lokasi penemuan. Sampel yang ada dalam kantong plastik tersebut dimasukkan ke dalam karung plastik. Sampel yang di ambil mewakili semua species yang ada. Sampel yang diperoleh dibius dengan alkohol $90 \%$ dan diawetkan dengan $70 \%$.

\section{Analisis Data}

Berdasarkan data sampel yang didapatkan di lapangan maka dilakukan analisis data dengan cara mendeskripsikan masing-masing species Amphibia tersebut. analisis data dibuat dalam bentuk tabel.

\section{HASIL}

Selama penelitian species dari familia Dicroglossidae yang ditemukan yaitu Fejervarya limnocharis Boie, Limnonectes ingeri Kiew, Limnonectes macrodon Dumeril \& Bibron, Limnonectes ibonorum, Limnonectes shompenorum. Umumnya ditemukan di aliran sungai (Tabel 1).

Tabel 1. Species Dicroglossidae yang tertangkap pada zona pemanfaatan Taman Nasional Kerinci Seblat (TNKS) jorong Pincuran Tujuh kecamatan Sangir kabupaten Solok Selatan.

\begin{tabular}{|c|c|c|c|}
\hline Genus & Species & Nama Nasional & $\sum$ \\
\hline Fejerfarya & 1. Fejervarya limnocharis Boie, 1835 & Katak tegalan & \\
\hline \multirow[t]{5}{*}{ Limnonectes } & 2. Limnonectes ingeri Kiew, 1978. & Bangkong batu & $\begin{array}{l}4 \\
4\end{array}$ \\
\hline & $\begin{array}{l}\text { 3. Limnonectes macrodon Dumeril \& } \\
\text { Bibron, } 1841\end{array}$ & Bangkong batu & 6 \\
\hline & 4. Limnonectes ibonorum Inger, 1964 & Bangkong punggung & 4 \\
\hline & $\begin{array}{l}\text { 5. Limnonectes shompenorum Das, } \\
1996\end{array}$ & Bangkong batu & 3 \\
\hline & Jumlah total & & 21 \\
\hline
\end{tabular}




\section{PEMBAHASAN}

\section{Deskripsi Spesies}

a. Fejervarya limnocharis Boie, 1835.

Fejervarya limnocharis Boie, Iskandar, 1998, Gb. 4e, Lf.18 hal. 73, Mistar, 2003, gb. 32, hal. 49, Mistar, 2008, gb. 22, hal.32. Kusrini, 2013, gb. 46a, hal. 70, Inger \& Stuebing, 2005, gb. 57, hal. 115.

F. limnocharis Boie yang ditemukan yaitu berukuran 44,20-56,80 mm. Katak ini biasanya disebut sebagai katak tegalan, hampir mirip dengan Fejervarya cancrivora, memiliki kepala runcing pendek. Memiliki sepasang bintil metatarsal. Tekstur kulit berkerut, tertutup bintil yang tipis, warna coklat keruh dengan bintil yang lebih gelap, kurang jelas seperti simetris, memiliki garis putih sepanjang tubuh. Jari kaki belakang berselaput setengah tepat pada ruas terahir, ujung jari tangan tumpul dan tidak melebar, sedangkan jari kaki meruncing yang tidak melebar, Urutan panjang jari kaki depan (UPJKD) III $>$ IV $>$ I $>$ II, urutan panjang jari kaki belakang (UPJKB) IV $>$ III $>$ V $>$ II $>$ I. ditemukan di aliran sungai yang berarus sedang. Ukuran PB 44,20-56,80 mm, PK 15,80-22,20 mm, LK 15,10-20,80 mm, DM 6,80-6,90 mm, DT 2,90-4,10 mm, JIN 4,80-6,10 mm, JIO 5,60-8,30 mm, PKD 19,60-22,10 mm, PTF 32,90-34,90 mm, 24,80-32,20 mm, 49,90-70,10mm, PM 7,50-9,20 mm. Contoh individu dari species F. limnocaris Boie terlihat pada Gambar 1.

Hasil yang ditemukan sesuai dengan yang dideskripsikan Iskandar (1998) species kecil, kepala runcing dan pendek, jari kaki setengah berselaput, tepat sampai pada ruas terakhir, mempunyai sepasang bintil metatarsal. Species ini identik dengan Fejervarya nov. Sp (species baru), kulit berbintil-bintil panjang jelas, ukuran lebih besar sedikit dari yang pertama. Jantan berukuran $50 \mathrm{~mm}$ dan betina sampai $60 \mathrm{~mm}$. Kulit berkerut, tertutup oleh bintil-bintil panjang yang tampak tipis. Bintil memanjang paralel dengan sumbu tubuh. warna tubuh kotor seperti lumpur dengan bercak-bercak yang lebih gelap yang kurang jelas tetapi simetris, kadang dengan warna kehijauan dan sedikit semu kemerahan. 


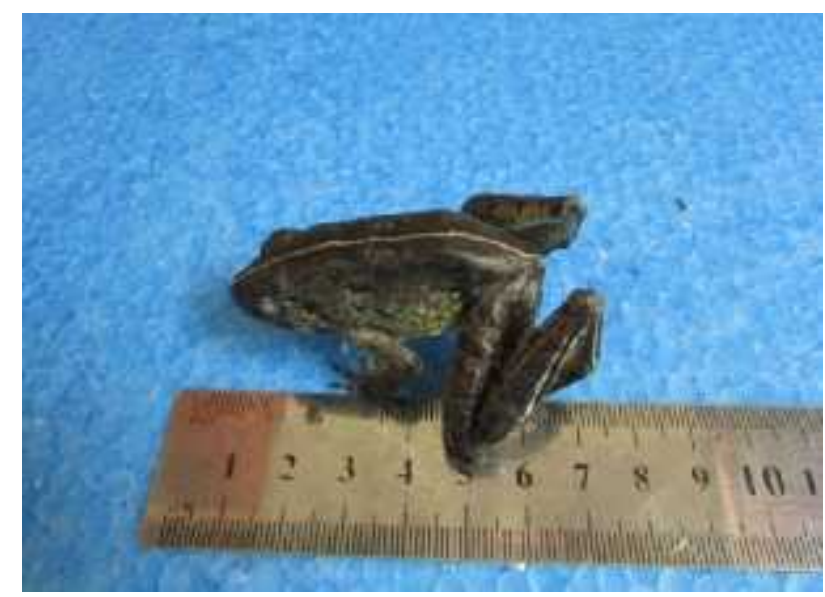

Gambar 1. Fejervarya limnocharis Boie, 1835.

b. Limnonectes ingeri Kiew, 1978.

Limnonectes ingeri Kiew, Inger \& Stuebing, 2005, gb. 63, hal. 123.

L. ingeri Kiew yang ditemukan berukuran 115,10-117,80 mm. Memiliki warna coklat kemerahan, timphanum terlihat jelas, lipatan supratimpanik terlihat jelas. Memiliki moncong yang panjang dan meruncing, terdapat bintil-bintil halus pada bagian tubuh. memiliki kaki yang besar, selaput renang penuh, ujung jari kaki membulat, urutan panjang jari kaki depan (UPJKD) III $>$ IV $>$ I $>$ II, urutan panjang jari kaki belakang (UPJKB) IV $>$ III $>$ V $>$ II $>$ I. Ditemukan diatas bebatuan sepanjang aliran sungai. Ukuran PB 115,10-117,80 mm, PK 47,20-49,20 mm, LK 49,10-50,90 mm, DM 10,10-12,10 mm, DT 8,40-9,80 mm, JIN 10,60-11,88 mm, JIO 14,40-16,10 mm, PKD 50,10-60,40 mm, PTF 64,10-66,10 mm, PF 44,22-46,70 mm, PKB 84,40-86,20 mm, PM 10,10-11,40 mm. Contoh individu dari species L. ingeri Kiew terlihat pada Gambar 2.

Hasil yang ditemukan sama dengan yang dideskripsikan oleh Inger \& Stuebing (2005) yaitu ditemukan di bebatuan sekitar aliran sungai, memiliki tubuh yang gemuk dan pendek, memiliki moncong yang meruncing, warna coklat kemerahan bata, namun bagian bawah berwarna putih kotor, tekstur kulit halus, memiliki kaki yang besar, lipatan supratimpanik terlihat jelas, kaki belakang berselaput penuh, terdapat bintil-bintil halus. 


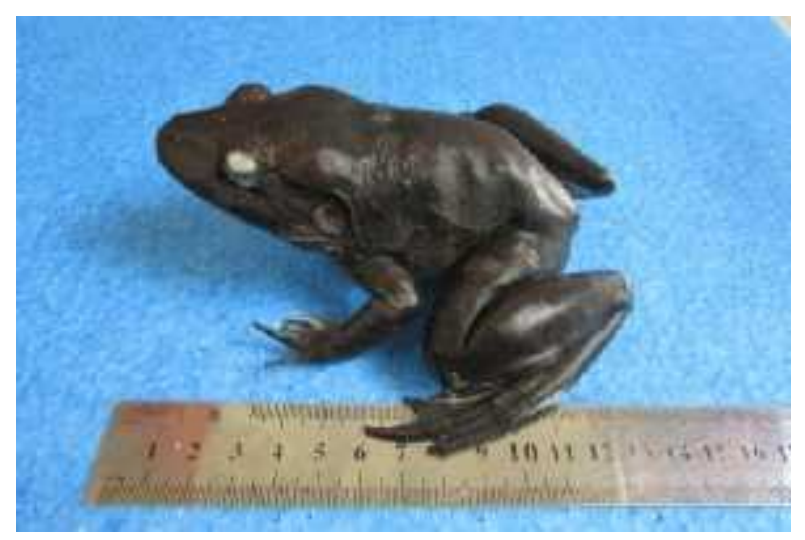

Gambar 2. Limnonectes ingeri Kiew, 1978

c. Limnonectes macrodon Dumeril \& Bibron, 1841.

Limnonectes macrodon Dumeril \& Bibron, Iskandar, 1998, gb.4g, Lf.18, hal. 75, Inger \& Stuebing, 2005, gb. 69, hal. 131, Mistar, 2008, gb. 27, hal. 36, Kusrini, 2013, gb. 52a, hal. 76.

L. macrodon Dumeril \& Bibron yang ditemukan betina berukuran 91,20105,22 mm. Katak ini biasanya disebut sebagai bangkong batu, ditemukan pada batu sekitar aliran sungai, warna coklat kehitaman. Tekstur kulit halus namun terdapat bintil-bintil kecil tersebar, dibelakang mata juga terdapat bintil kecil, kerongkongan abu-abu, moncong tumpul, memiliki kepala yang melebar dan panjang, timpanum jelas. memiliki jari-jari yang besar dan jelas, ujung jari kaki melebar, jari kaki berselaput penuh selaput melebar pada jari kedua dan ketiga dikedua sisinya, urutan pajang jari kaki depan (UPJKD) III $>$ I $>$ IV $>$ II, urutan panjang jari kaki belakang (UPJKB) IV >III >V > II >I. Ukuran PB 91,20-105,22 mm, PK 40,10-42,60 mm, LK 38,90-41,20 mm, DM 9,80-11,10 mm, DT 7,70-9,10 mm, JIN 8,90-11,12 mm, JIO 5,80-7,20 mm, PKD 43,20-45,60 mm, PTF 60,20-63,10 mm, PF 39,10-41,80 mm, PKB 74,10-76,80 mm, PM 6,40-8,10 mm. Contoh individu dari species L. macrodon Dumeril \& Bibron terlihat pada Gambar 3.

Hasil yang ditemukan sesuai dengan yang dideskripsikan Iskandar (1998) Katak yang sangat besar dengan kepala yang besar, terutama pada spesimen jantan, kulit halus, dengan beberapa bintil kecil tersebar, bagian belakang pelupuk mata terdapat bintil-bintil, jari kaki berselaput sampai keujungnya. Spesimen dewasa bervariasi dari $100 \mathrm{~mm}$ sampai $150 \mathrm{~mm}$. Tekstur halus, hanya terdapat sedikit sekali bintil-bintil bertebaran, warna biasanya secara seragam berwarna coklat kemerahan 
sampai coklat kehitaman, biasanya terdapat di sepanjang sungai atau sungai kecil yang jernih.

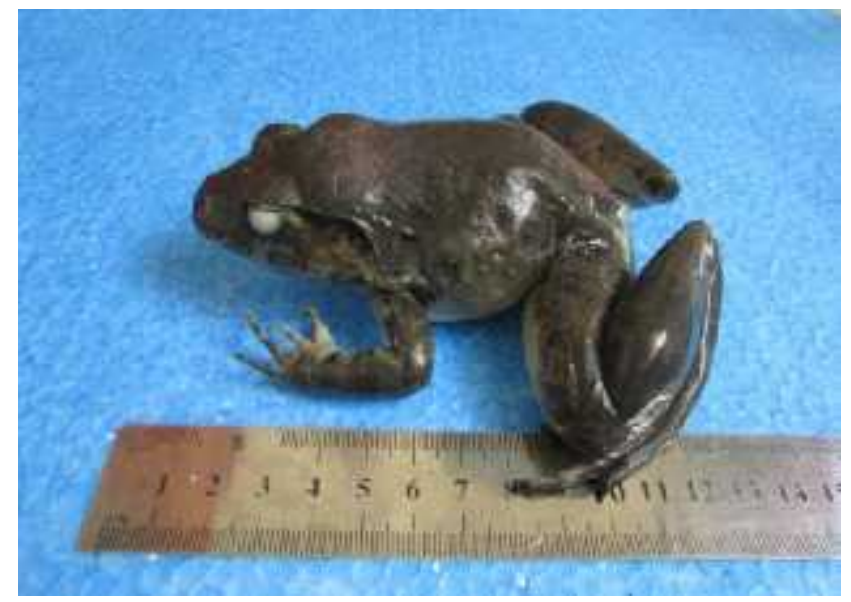

Gambar 3. Limnonectes macrodon Dumeril \& Bibron, 1841.

\section{d. Limnonectes ibanorum Inger, 1964.}

Limnonectes ibanorum Inger, Inger \& Stuebing, 2005 , gb. 62, hal. 122, Mistar, 2008, gb. 23, hal. 33 .

Limnonectes ibanorum Inger yang ditemukan berukuran 82,40-84,20 mm. Katak ini biasanya disebut sebagai bangkong batu, berukuran besar, moncong tajam, warna tubuh coklat, memiliki kaki yang besar, bagian bawah memiliki warna keputihan dengan noktah-noktah, tekstur kulit licin, namun terdapat lipatan-lipadan pada bagian punggung, memiliki mata yang besar. memiliki kaki yang kekar, selaput jari kaki belakang penuh hingga ruas terakhir, urutan panjang jari kaki depan (UPJKD) III $>$ I $>$ IV $>$ II, urutan panjang jari kaki belakang (UPJKB) IV $>$ III $>$ V $>$ II $>$ I. ditemui di bebatuan sekitar sungai. Ukuran PB 82,40-84,20 mm, PK 36,20-38,10 mm, LK 28,80-30,20 mm, DM 5,70-7,60 mm, DT 7,60-9,10 mm, JIN 8,50-10,10 mm, JIO 4,80-6,90 mm, PKD 32,20-34,80 mm, PTF 48,10-50,30 mm, PF 35,4037,20 mm, PKB 61,90-63,20 mm, PM 8,90-10,10 mm. Contoh individu dari species L. ibonorum Inger terlihat pada Gambar 4.

Hasil yang ditemukan sesuai dengan yang dideskripsikan Mistar (2008) Katak berukuran panjang antara 80-101 mm, jari kaki depan bulat, melekuk dan tanpa selaput meskipun mempunyai kulit yang dapat membuka dan melipat pada bagian tepi dari jari kedua dan ketiga, jari belakang berselaput hingga ruas terahir. 
Tekstur tubuh bagian tubuh belakang mempunyai deretan-deretan lipatan kulit yang tersusun paralel. Umumnya berwarna coklat, tenggorokkan dan dada berwarna keputihan dengan noktah-noktah gelap. Umumnya dijumpai di sungai-sungai yang jernih, berbatu dan lebar, dijumpai dalam hutan primer maupun hutan sekunder tua.

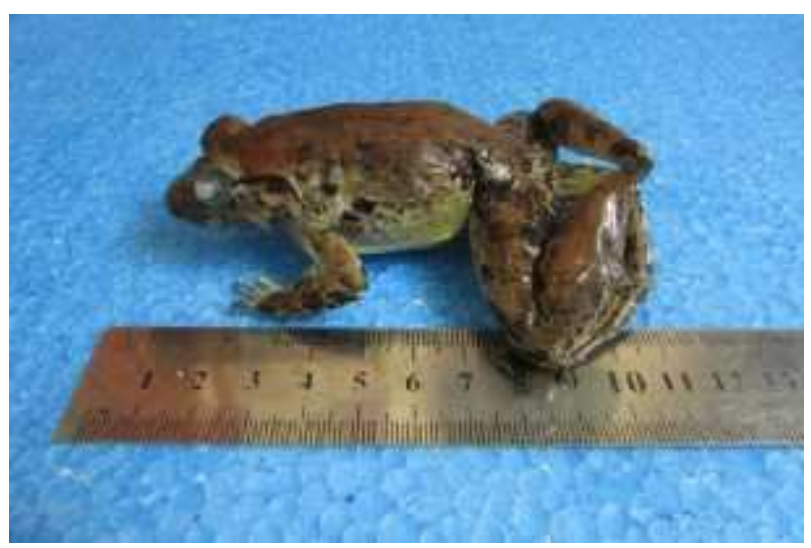

Gambar 4. Limnonectes ibonorum Inger, 1964.

e. Limnonectes shompenorum Das, 1996.

Limnonectes shompenorum Das, Mistar, 2003, gb. 36, hal. 54.

L. shompenorum Dasyang ditemukan yaitu berukuran besar berkisar 107,80-109,22 mm (3 individu). Ditemukan dialiran sungai, berwarna coklat muda, memiliki kepala yang besar dengan adanya tonjolan dibagian kepala, moncong tajam. warna bagian bawah tubuh berwarna krem kotor, tekstur kulit halus memiliki binti-bintil pada bagian punggung hingga sisi tumbuh. jari kaki belakang berselaput penuh, urutan panjang jari kaki depan (UPJKD) III $>$ IV $>$ I $>$ II), urutan panjang jari kaki belakang (UPJKB) IV >III > V > II $>$ I. Ukuran PB 107,80-109,22mm, PK 38,9040,60 mm, LK 43,30-50,50 mm, DM 10,10-11,80 mm, DT 8,10-9,80 mm, JIN 7,808,90 mm, JIO 10,20-12,10 mm, PKD 40,90-43,10 mm, PTF 56,80-59,20 mm, PF 42,10-44,80 mm, PKB 74,10-76,40 mm, PM 9,10-10,20 mm. Contoh individu dari species L. shampenorum Das terlihat pada Gambar 5.

Hasil yang ditemukan sesuai dengan dideskripsikan Mistar (2003) Katak berukuran besar, miirip dengan Limnonectes blytii, tekstur kulit halus dan sedikit bintil-bintil pada bagian sisi tubuh, warna bagian atas tubuh coklat muda sampai coklat tua, bagian bawah tubuh berwarna cream kotor sampai keperakan, biasanya 
ditemukan di hutan sekunder, sungai yang tidak mengalir, banyak ditumbuhan herba sekitarnya.

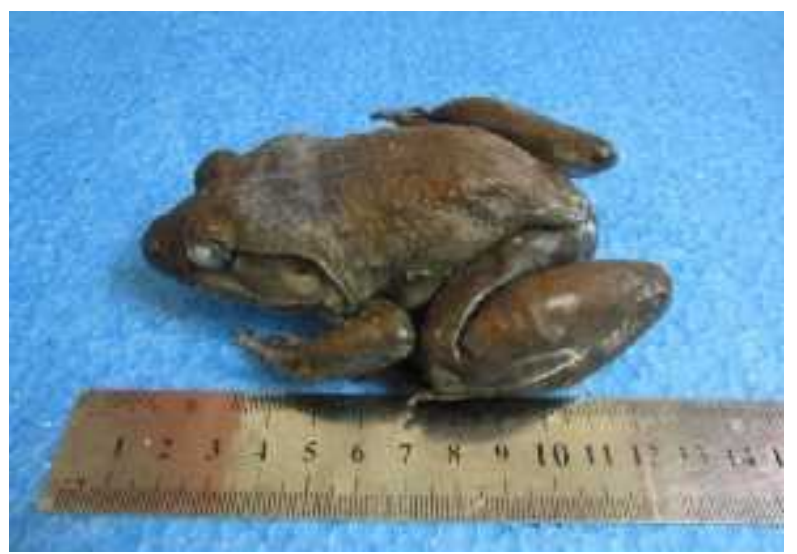

Gambar 5. Limnonectes shampenorum Das, 1996.

Amphibia selalu berasosiasi dengan air (Iskandar, 1998). Amphibia memerlukan air untuk bertelur dan berkembang, Kanna (2005) mengatakan bahwa secara umum, katak dapat hidup di sembarang tempat, baik pantai maupun dataran tinggi, dengan suhu air antara $20^{\circ}-35^{\circ}$ C. Jumlah species Amphibia pada Zona pemanfaatan TNKS jorong Pincuran Tujuh kecamatan Sangir kabupaten Solok Selatan lebih sedikit diduga hilangnya hutan dan lahan basah sebagai habitat dan tempat siklus hidup larva dari Amphibia. Hilangnya hutan dan lahan basah (kubangan) yang biasanya terbentuk setelah hujan di sekitar hutan yang merupakan habitat alami dari species Amphibia. Kusrini (2007) menemukan hilangnya hutan dapat memusnahkan species-species yang sangat tergantung pada keberadaan habitat tersebut, hilangnya lahan basah sama dengan hilangnya Amphibia. Ahmad dan Ibney (2015) penyebab utama turunnya populasi adalah karena eksplotasi alam seperti penebangan hutan, banjir dan penggunaan pestisida yang terus meningkat. Selain itu, pertumbuhan penduduk yang terus meningkat, penyakit, perubahan suhu bumi dan peningkatan radiasi $\mathrm{UV}$.

Familia Dicroglossidae merupakan katak dengan anggota species berbentuk gemuk, otot kaki belakang besar dan bulat serta kaki umumnya dengan ujung jari yang membulat, jari-jari kaki depan umumnya tidak berselaput, sedangkan selaput jari kaki belakang umumnya separuh atau melebar hingga ke ujung jari. Familia ini kebanyakan ditemukan di sekitar sungai-sungai kecil dan sungai tidak mengalir di dalam hutan sekunder (Mistar, 2008). 


\section{KESIMPULAN}

Amphibia yang ditemukan pada zona pemanfaatan TNKS jorong Pincuran Tujuh kecamatan Sangir kabupaten Solok Selatan terdiri dari 5 Dicroglossidae yaitu Fejervarya limnocharis, Limnonectes ingeri, Limnonectes macrodon, Limnonectes ibonorum, Limnonectes shampenorum.

\section{DAFTAR PUSTAKA}

Ahmad, F. Dan S. M. Ibney. 2015. Frog in The Genus Fejervarya (Anura: Dicroglossidae) of The Nazipur Area, Patnitala Upazila, Naogaon District In Northwestern Bangladesh. IRCF Reptiles \& Amphibians 22(4):145-149.

Anonim. 2015. Laporan Tahunan. Seksi Pengelolaan TN Wilayah IV: Bidang Pengelolaan TN wilayah II Sumatera Barat. Balai Besar Taman Nasional Kerinci Seblat: Sangir.

Brotowidjoyo, M.D. 1994. Zoologi Dasar. Jakarta: Erlangga.

Inger, R. F and Stuebing, R. B. 2005. Frogs of Borneo. Natural Hystory Publications (Borneo). Kota Kinabalu.

Iskandar, D. T. 1998. Amfibi Jawa dan Bali. Terjemahan oleh Martodihardjo. Puslitbang Biologi. LIPI.

Kanna, I. 2005. Bullfrog Pembenihan dan Pembesaran-Seri Budidaya. Kanisius. Yogyakarta.

Kurniati, H. 2008. Jenis-Jenis Kodok Berukuran Besar Yang Dapat Dikonsumsi Dan Mampu Beradaptasi Dengan Habitat Persawahan di sumatera. Jurnal fauna Indonesia. Vol 8(1) 2008: 6-9.

Kusrini, M. D. 2007. Konservasi Amphibia Di Indonesia: Masalah Global Dan Tantangan. Jurnal media konservasi. Vol XII. Hlm. 89-95.

Mistar. 2003. Panduan Lapangan Amfibi Kawasan Akosistem Leuser. LIPI-NGO Movenent. Bandung.

Wanda, I. F. 2012. Jenis-Jenis Anura (Amphibia) di Hutan Harapan Jambi. Jurnal Biologi Universitas Andalas. Vol 1 (2) Desember 2012: 99-107. 